\title{
The Corrosion Studies of Electron Beam Welded Nickel Alloy
}

\author{
M. Sroka ${ }^{1}$, E. Jonda ${ }^{1, a}$, M. Węglowski ${ }^{2}$ and S. Błacha ${ }^{2}$ \\ ${ }^{1}$ Silesian University of Technology, Institute of Engineering Materials and Biomaterials, 18A Konarskiego Str., \\ 44100 Gliwice, Poland \\ ${ }_{2}^{2}$ Institute of Welding, 16/18 Bt. Czesława Str., 44100 Gliwice, Poland
}

\begin{abstract}
The paper presents the influence of electron - beam (EB) remelting effect on the surface layer electrochemical parameters obtained from potentiodynamic anodic polarization studies and impedance spectroscopy measurements for a set of Inconel 617 electron beam remelted obtained for different process parameters. The correlation between EBW process parameters and characteristic of surface oxide layer properties and resistance to the acidic environment were discussed. The electrochemical studies were supported by microstructural analysis of the remelted zone (RZ), heat affected zone (HAZ), native metal and observed precipitates formed under rapid solidification process. Both electrochemical technics applied to evaluate corrosion properties of remelted Inconel 617 evidenced a strong influence of the electron beam current on the corrosion resistance.
\end{abstract}

\section{Introduction}

The studies conducted up to now have been mainly focused on the technology of joining nickel alloys by EBW welding. The EB remelting process is still weakly studied in the literature. The main problems of welding considering nickel base alloys include the tendency to hot cracking of crystallization and liquation type, wherein the crystallization cracks can develop in the weld axis or may be arranged in the transverse direction and also may be present as a micro - cracks. The liquation cracks are mainly located in the near weld area of heat affected zone (HAZ). The cause of hot cracks are the liquid phases present on the grain boundary with a lower melting temperature, along which occurs the metal decohesion due to shrinkage stresses during crystallization and cooling of the weld [1-7].

From the view point of the corrosion resistance of an EB remelted layer, severe galvanic corrosion could take place in the fusion zone or HAZ due to their very small anodic areas when the corrosion potential of both zones is more active than the adjacent base material [8]. Occurring corrosion processes are always connected to microstructural inhomogeneity resulting from alloying element partitioning between present phase and formation of complex precipitates [9-10]. Although excellent microstructural features, heat and mechanical properties of electron beam weldments, corrosion resistance is also one of the most important factors in evaluation of long term life service of Inconel

\footnotetext{
${ }^{\mathrm{a}}$ Corresponding author : ewa.jonda@polsl.pl
} 
alloys. Many authors postulated that evaluation of corrosion resistance is absolutely essential to prevent premature damages of weldments [11-13].

In the present paper, the influence of basic electron beam remelting process parameters on the resistance to the acidic environment and selected surface properties were discussed.

\section{Experimental conditions}

In the present study, the Inconel alloy 617 has been electron beam remelted. The electron beam (EB) remelting of Inconel 617 alloy has been performed on the universal EB welding system type XW150:30/756 (Cambridge Vacuum Engineering). The base material Inconel 617 alloy was supplied in the form of a solution treated and a water quenched plate of the thickness of $1.0 \mathrm{~mm}$. Six weld beads were produced on the surface with parameters: beam current: $1 \mathrm{~mA}, 1.5 \mathrm{~mA}, 2 \mathrm{~mA}, 2.5 \mathrm{~mA}$, $3 \mathrm{~mA}, 3.5 \mathrm{~mA}$; accelerating energy: $120 \mathrm{kV}$, remelting velocity: $500 \mathrm{~mm} / \mathrm{min}$., and focus: $496 \mathrm{~mm}$. The corrosion behaviors of welded nickel 617 alloy were evaluated by analyzing the polarization curves and electrochemical impedance spectroscopy. Metallographic investigations were made with the Leica light microscope at magnifications $10-1000 x$. The metallographic studies were performed on the scanning electron microscope Zeiss Supra 35. Analysis of the chemical composition was performed using an ARL3460 spectrometer. Specimens of remelted Inconel 617 were observed also under TEM in order to midentify present precipitates. The TEM experiments were performed on the TITAN FEI 80 - 300KV Probe Corect.

\section{Results and discussion}

The electron beam remelting of the INCONEL 617 surface layer resulted in the formation of three different zones: the remelted zone (RZ), the heat affected zone (HAZ) and the base metal (BM) one. The so - called fusion line also was formed by melting of grains of HAZ (Fig. 1).

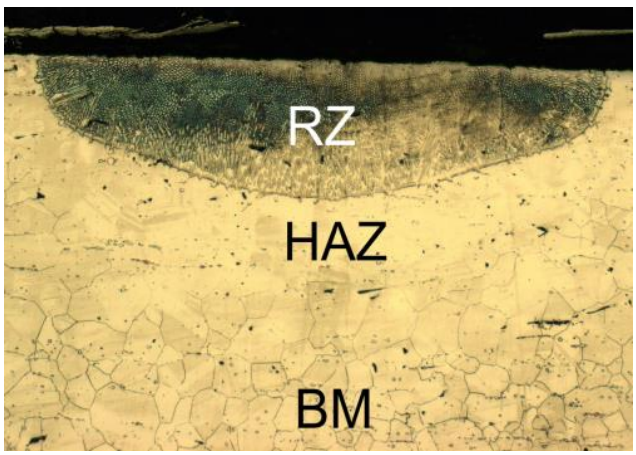

Figure 1. Remelted and the heat affected zone of the surface layer of INCONEL 617, beam current: $1 \mathrm{~mA}$.

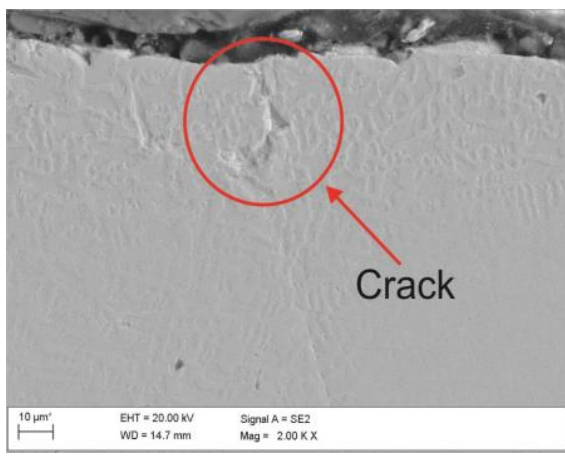

Figure 2. Microstructure of Inconel 617 alloy remelting by electron beam with a visible crack in remelting zone, beam current $1.5 \mathrm{~mA}$.

The geometrical parameters of the weld bead have been studied. The lowest width of remelted weld face of $821.71 \mu \mathrm{m}$ was obtained for EB remelting at the beam current of $1 \mathrm{~mA}$, while the highest $2479.78 \mu \mathrm{m}$ for welding current $3.5 \mathrm{~mA}$. Analogically the minimum remelting depth of $193.4 \mu \mathrm{m}$ was achieved at $1 \mathrm{~mA}$ beam current, while the highest $1137.27 \mu \mathrm{m}$ when $3.5 \mathrm{~mA}$ beam current was applied. It can be concluded that the beam current value has a significant influence on the remelted weld face width and remelting depth and its increase results in an increase of both parameters. The microstructure of EB remelted Inconel 617 reveled presence of singular cracks that extends transversely to the axis of the remelted zone (RZ). Microstructure made by electron beam remelting with a visible crack in remelting zone is shown in Figure 2 . Due to the place of origin, it can be concluded that it is a hot crack, caused by rapid solidification process. Such crack may occur because crystallized metal is under the influence of the tensile stresses arising from the uneven cooling of the 
heated material. Because of present stresses, the metal deforms, and insufficient capacity to deformation causes it's cracking. Hot cracks are one of the most common defects that occur during the surface modification by electron beam or after a certain time after the treatment, but before external stresses from service loads [8].

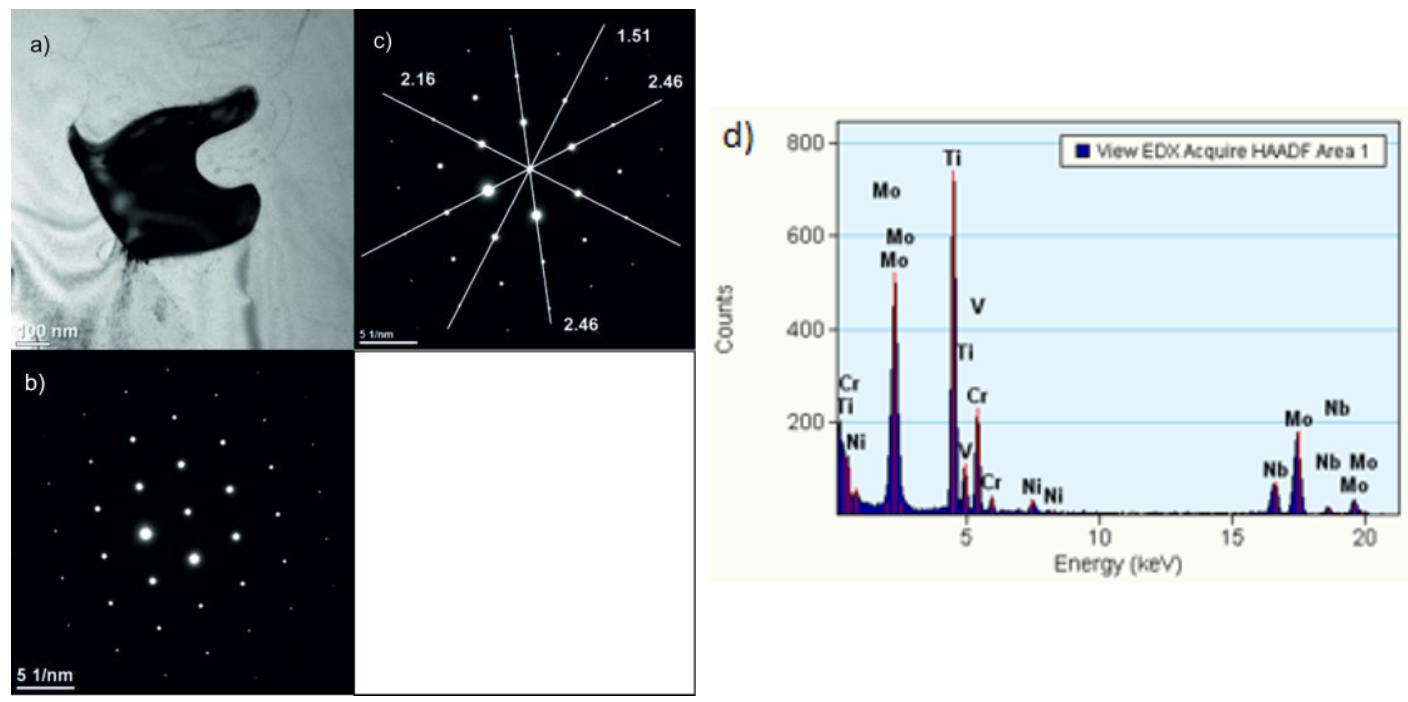

Figure 3. The thin foil structure of Inconel 617 alloy after EB remelting, beam current $3 \mathrm{~mA}$; a) bright field, b) diffraction pattern of the area showed in fig a) and c) solved diffraction of the area showed in fig a), d) spectrum obtained by EDS analysis.
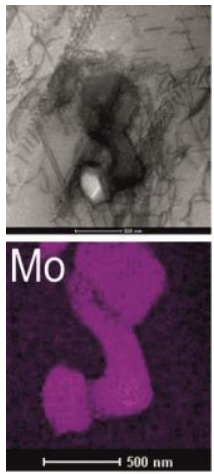
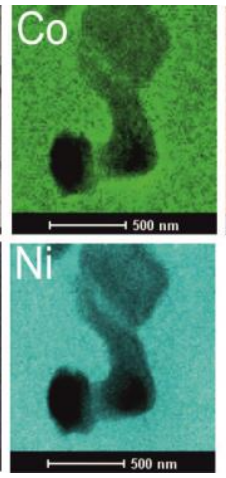
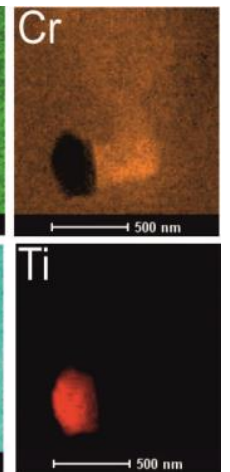

Figure 4. Elemental map distribution of carbide precipitates of EB remelting Inconel 617 alloy (at beam current of $3 \mathrm{~mA}$ ), (HAADF - The High Angle Annular Dark Field detector).

Based on the thin foil studies in a transmission electron microscope it was found, that in the electron beam remelted material (at the beam current of $3 \mathrm{~mA}$ ) is the precipitates of ( $\mathrm{Mo}, \mathrm{Ti}) \mathrm{C}_{2}$. The orientation of the precipitates with respect to the beam was [01-1] (Fig. 3). Precipitates of (MoTi) $\mathrm{C}_{2}$ can be checked in the card number 01-071-6035. The results of mapping of the chemical elements distribution (Fig. 4) also shows the significant increase of Ti and Mo and smaller of Cr in vicinity of precipitates concentration in comparison to the base material.

The microstructural studies on SEM revealed that the morphology of EB remelted zone shows cellular - dendritic microstructure. The dendritic growth occurs according to the direction of heat dissipation from the border of the remelted zone (RZ) and the heat affected zone (HAZ). The microstructure of the remelted zone are presented in Figures 5-6. The remelted zone shows columnar crystals and dendritic cells crystallizing in the direction of heat dissipation. The microstructure of EB remelted Inconel 617 alloy at low beam power $(1 \mathrm{~mA})$ shows typical dendritic microstructure of fast crystalizing alloy, where formed cellular - dendritic grains are small and preferentially more rectangle 
(Fig. 6 a). In the case of higher beam power during EB remelting (i.e. $3.5 \mathrm{~mA}$ ) formed grains in remelted zones are preferentially more elongated and bigger than for lower remelting energies (Fig. 6 b). Performed microstructural analysis not reveled any other precipitates in interdendritic regions, proving full dissolution of primary carbides during remelting and lack of their precipitation during cooling form remelting temperature.
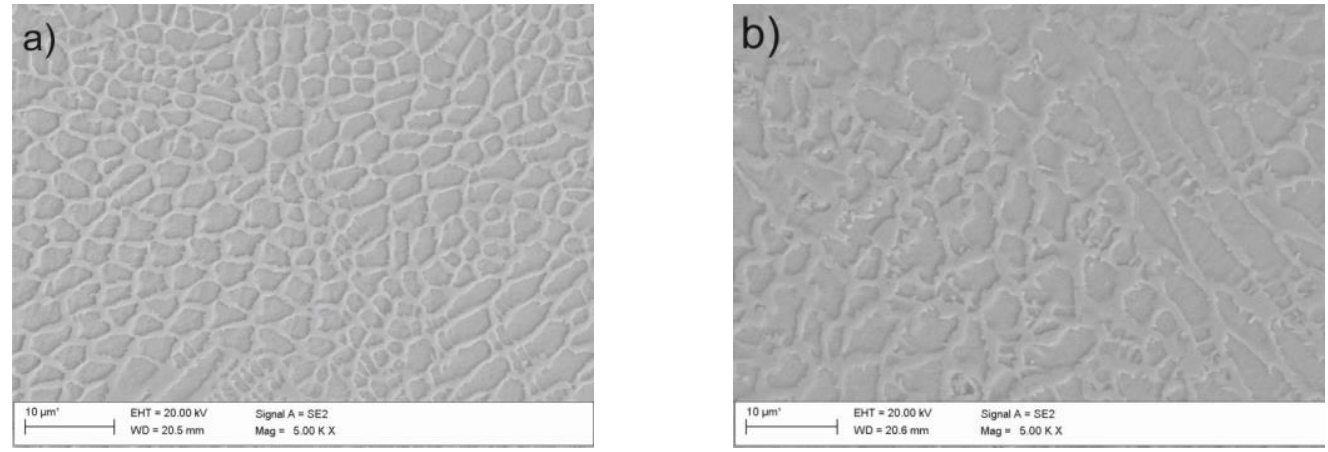

Figure 5. SEM micrographs of Inconel 617 alloy, beam current: a) $1 \mathrm{~mA}$, b) $2.5 \mathrm{~mA}$.
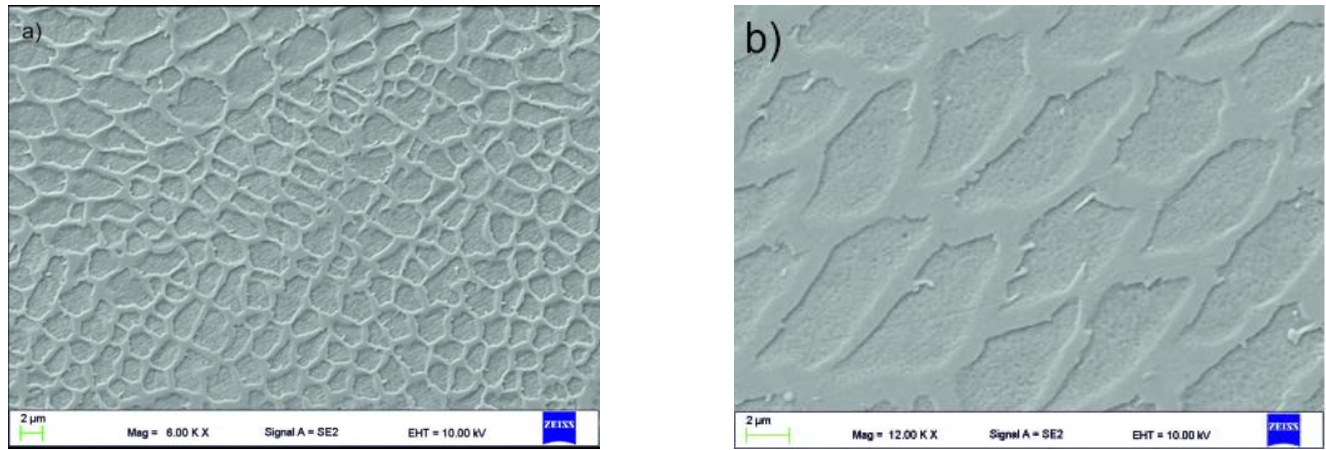

Figure 6. The microstructure in the centre of remelted zone of Inconel 617 alloy remelted with electron beam power of: a) $1 \mathrm{~mA} \mathrm{b)} 3.5 \mathrm{~mA}$.

Both electrochemical technics applied to evaluate corrosion properties of remelted Inconel 617 evidenced a strong influence of the electron beam current on the corrosion resistance. It must be remembered that during the potentiodynamic test the sample surface got alteration while the EIS method introduces smaller perturbation to tested system. The EIS parameters analysis and Nyquist and Bode plots confirmed the decreasing resistance character (R2 parameter) of the remelted surface, thus worst passivation ability in the test $1 \mathrm{M} \mathrm{NaCl}$ solution. The Nyquist plots (Fig. 7a) of EIS data show changes in the slope of the impedance $\mathrm{Z}$ curve of the remelted surfaces. The general trend of decreasing impedance with the increase of applied beam current was observed, indicating thickening of the passive layer lower resistant character.

The best curve characteristic was registered for a parent metal, not EB remelted. The EIS Bode phase angle plots (Figs. $7 \mathrm{~b}$ and $7 \mathrm{c}$ ) shows high phase angles over an intermediate frequency range with sudden follow at high rang for the parent metal, typical for a passivated surface. The Bode plots show typical capacitive like behaviour, where the phase angle maximums are smaller than $80^{\circ}$ what can be interpreted as a deviation from ideal capacitator behaviour. The Bode plot analysis confirms the resistive nature of studied surfaces, as evidenced by the phase angle value close to 0 and almost constant value of $\log \mathrm{Z}$ in the high-frequency range. The Bode characteristic was changed after EB remelting, the phase angle curve shows high values in the high-frequency range.The potentiodynamic polarisation curves (Fig. 8) revealed a shift to positive values of corrosion potential $\left(\mathrm{E}_{\text {corr }}\right)$ for small electron beam current welds (beam current $1.5-2.5 \mathrm{~mA}$ ), while for higher $(3 \mathrm{~mA})$ it was returned to 
the values of the parent metal and exceeded it for a maximum EB energy (3.5 mA). Similarly, with EB current increase, the polarization resistance $\left(R_{p}\right)$ decreased and increased corrosion current density $\left(\mathrm{i}_{\text {coor }}\right)$ revealing deterioration of corrosion resistance of EB remelted Inconel alloy. The increase of EB beam current resulted in gradual decrees of the repassivation potential $\left(\mathrm{E}_{\mathrm{REP}}\right)$ from positive to negative values.

a)

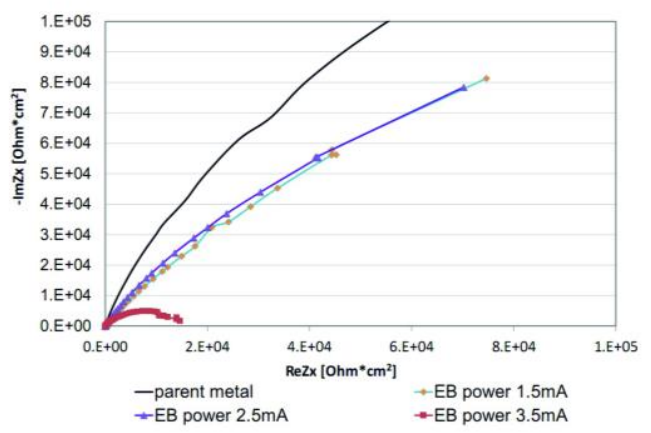

c) b)

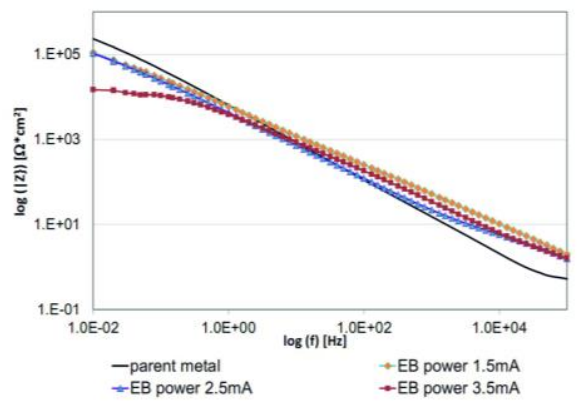

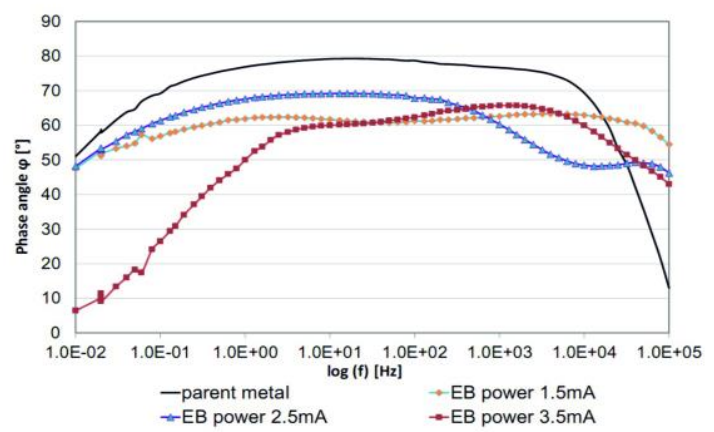

Figure 7. EIS of Inconel 617 - the parent metal and welds at different electron beam power, a) Nyquist plot, b) Z modulus and c) Bode phase-angle plot.

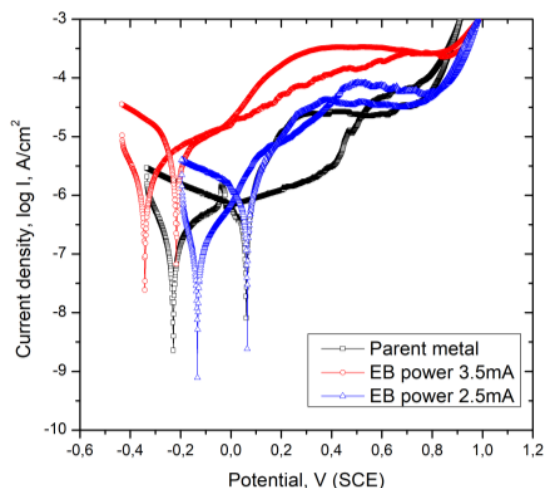

Figure 8. Potentiodynamic polarization curves of $\mathrm{EB}$ welded Inconel alloy 617 in $1 \mathrm{MNaCl}$ at different electron beam power.

\section{Summary}

On the basis of test results, it was found that: 
1. The microstructure of remelted zone shows cellular - dendritic microstructure, where for low electron beam power formed crystals are small and rectangular that's grown with applied energy showing more elongated form.

2. During electron beam remelting of Inconel 617 alloy singular cracks were observed, that extends transversely to the axis of the remelted zone (RZ). Due to the place of origin, it can be classified as hot crack, caused by rapid solidification process.

3. With the increase of electron beam power, the thickness of the remelted zone (RZ) and width of remelted surface increased.

4. The corrosion resistance of the surface, evaluated by means of EIS and polarization curves analysis, was strongly deteriorated after EB remelting.

\section{Acknowledgements}

This research was financed within the framework of the statutory financial grant supported by the Faculty of Mechanical Engineering of The Silesian University of Technology.

\section{References}

1. J. Nowacki, K. Pietrzak, An overview of welding 11, 22 (2012)

2. M. Lachowicz, W. Dudziński, M. Podrez - Radziszewska, Mater. Charact. 59, 560 (2008)

3. M. Shakil, M. Ahmad, N.H. Tariq, B.A. Hasan, J.I. Akhter, E. Ahmed, M. Mehmood, M.A. Choudhry, M. Iqbal, Vac. 110, 121 (2014)

4. J. Kusiński, J. Blicharski, M. Cieniek, Ł. Dymek, S. Rozmus-Górnikowska, M. Solecka, M. Faryj, Mater. Eng. 36, 363 (2015)

5. T. Wang, N. Li. Z. Yhang Vac. 149, 29 (2018)

6. K.D. Ramkumar, R. Sridhar, S. Periwal, S. Oza, V. Saxena, P. Hidad, N. Arivazhagan, Mater. Des. 68, $158(2015)$

7. C. Wieding, C. Lochbichler, N. Enzinger, C. Beal, C. Proc. Engineering 86, 184 (2014)

8. S. A. David, J. M. Vitek, S.S. Babu, Sci. and Techn. of Welding and Joining 2, 79 (1997)

9. M. Lucas, JR., C.E Jackson, Welding Research Supplement, 46 (1970)

10. L.Y. Xu M. Li, H. Y. Jing, Y. D. Han, Int. Jour. Electrochem. Sci. 8, 2069 (2013)

11. K. Łyczkowska, J. Michalska, Arch. of Met. and Mat. 6 (2), 653 (2017)

12. G. Fuyang, G. Peng, J. Zhiying, Z. Liu, Z.Liao, Int. Jour.of Light Weight Mat. And Man. (to be published) (2018)

13. S. Schmigalla, S. Krasnorutskyi, M. Zinke, A. Heyn, Mat. and Corrosion 66 (5) (2015) 